05

\title{
Влияние магнитного поля удлиненного соленоида на деформирование металлических кумулятивных струй
}

\author{
(C) С.В. Федоров \\ Московский государственный технический университет им. Н.Э. Баумана, \\ 105005 Москва, Россия \\ e-mail: sergfed-64@mail.ru
}

Поступило в Редакцию 5 декабря 2019 г.

В окончательной редакции 20 февраля 2020 г.

Принято к публикации 20 февраля 2020 г.

Рассмотрено инерционное удлинение металлической кумулятивной струи в магнитном поле удлиненного соленоида. Целью воздействия магнитного поля на кумулятивную струю является замедление развития пластической неустойчивости струи с увеличением ее предельного удлинения и пробивной способности. С использованием ряда упрощающих допущений получено аналитическое описание электромагнитных процессов в участке струи при его движении в полости соленоида и после выхода из нее. Рассчитаны индукционный нагрев участка струи и напряженное состояние в нем при действии электромагнитных сил применительно к условиям проводившихся ранее экспериментов с воздействием магнитного поля соленоидов на кумулятивные струи. Полученные результаты используются для обоснования гипотезы о возможной причине большого расхождения в экспериментальных данных разных авторов по приросту пробивного действия кумулятивных зарядов.

Ключевые слова: кумулятивный заряд, кумулятивная струя, пробивное действие, пластическая неустойчивость, магнитное поле, соленоид, индукционный нагрев.

DOI: 10.21883/JTF.2020.10.49800.388-19

\section{Введение}

Кумулятивные струи (КС), формируемые тонкими металлическими оболочками осесимметричной формы при их обжатии продуктами детонации заряда взрывчатого вещества, обладают высокой скоростью и способны пробивать преграды значительной толщины [1-4]. При формировании КС из медных конических облицовок скорость их головной части может составлять до $10 \mathrm{~km} / \mathrm{s}$, а глубина пробития ими стальной преграды достигает 10 диаметров кумулятивного заряда (К3) в случае прецизионной технологии его изготовления $[5,6]$.

Скорость различных участков КС возрастает от „хвоста“ струи к ее „голове“. Вследствие наличия указанного градиента скорости сформировавшаяся КС в процессе своего движения сначала деформируется с сохранением сплошности и увеличением длины. Однако впоследствии происходит распад КС в осевом направлении на множество отдельных элементов, которые уже не деформируются и движутся в дальнейшем как абсолютно твердые тела до момента взаимодействия с преградой [7]. В соответствии с гидродинамической теорией проникания пробивное действие КС определяется ее длиной и плотностью материала [5]. Поэтому предельная толщина преграды, которую может пробить КС, зависит от суммарной длины тех безградиентных элементов, на которые она разделилась $[8,9]$.

\section{1. Распад кумулятивных струй}

Характер разделения КС на отдельные элементы и степень ее удлинения до момента разделения зависят от физико-механических свойств материала кумулятивной облицовки. При использовании облицовок из металлов с относительно невысокими пластическими свойствами, например стальных, осевой распад формируемых ими КС происходит квазихрупким образом со свойственной ему ломаной формой поверхностей разделения элементов, ориентированных часто наклонно по отношению к оси струи (рис. 1,a) [10]. Сами элементы распавшейся КС при квазихрупком разрушении также часто имеют неправильную компактную либо слабо вытянутую вдоль оси струи форму. Квазихрупкое разрушение реализуется

$a$

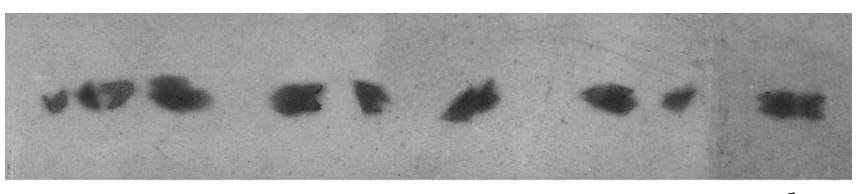

$b$

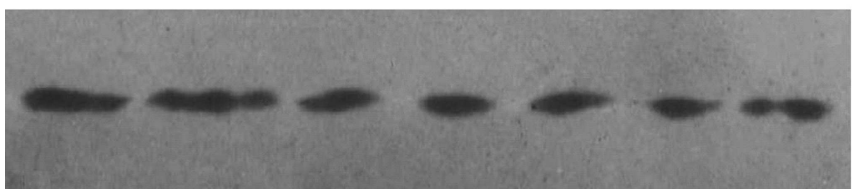

Рис. 1. Рентгенограммы распада КС по квазихрупкому $(a)$ и пластическому $(b)$ механизмам. 
на достаточно ранних стадиях растяжения КС, так что ее удлинение на момент разрушения относительно невелико, как невелико вследствие этого и пробивное действие струи.

Существенно более высокое предельное удлинение имеют КС, сформированные с использованием облицовок из высокопластичных металлов. К числу последних относится медь, наиболее часто применяемая для изготовления кумулятивных облицовок, так как наряду с высокими пластическими свойствами обладает также еще и достаточно высокой плотностью. Распад на отдельные элементы КС из высокопластичных металлов может быть охарактеризован, как пластический $[11,12]$. Ему свойственны следующие основные особенности. На некоторой стадии инерционного удлинения КС начинается развитие пластической неустойчивости струи, реализующееся в форме появления на струе многочисленных „шеек“. В местах шейкообразования происходит локализация деформаций в струе с ускоренным уменьшением радиуса „шеек“ вплоть до нулевого значения, в результате чего и происходит разделение КС на отдельные элементы. Элементы распавшейся пластическим образом КС имеют правильную вытянутую вдоль оси струи веретенообразную форму с заостренными передним и задним краями (рис. $1, b)$ [10]. Коэффициент предельного удлинения участков медных КС, характеризующий отношение длины участка струи в момент его разделения на отдельные элементы к начальной длине в момент формирования участка при схлопывании облицовки, может иметь значения на уровне нескольких десятков [13], что значительно выше, чем у стальных КС, разрушающихся по квазихрупкому механизму. Этим и обеспечивается высокое пробивное действие КЗ с медными облицовками.

\section{2. Использование электромагнитных воздействий}

Специалистами в области кумулятивного взрыва проводится поиск путей повышения пробивного действия КЗ. В качестве одного из таких путей нетрадиционного характера рассматривается использование электромагнитных воздействий в процессе кумулятивного взрыва. С помощью электромагнитных воздействий, осуществляемых на различных стадиях функционирования КЗ, можно обеспечить как снижение [14-19], так и повышение [20-22] его пробивного действия. В качестве воздействия, ориентированного на увеличение пробития К3, рассматривается воздействие на растягивающуюся КС в свободном полете продольного магнитного поля $[21,23,24]$. Целью такого электромагнитного воздействия на разрушающуюся пластическим образом КС является замедление развития пластической неустойчивости струи с увеличением ее предельного удлинения. Стабилизирующее влияние магнитного поля на процесс растяжения КС связывается с двумя факторами. Вопервых, при деформировании КС в продольном магнитном поле на нее действуют дополнительные радиальные электромагнитные силы, распределенные по длине КС таким образом, что они препятствуют развитию „шеек“ [20]. Во-вторых, за счет циркуляции в КС вихревых азимутальных токов, индуцирующихся магнитным полем, происходит джоулев разогрев материала струи, ведущий к снижению его прочностных свойств (эффект термического разупрочнения) [25]. Следствием термического разупрочнения материала КС должно также являться замедление развития „шеек“.

Следует отметить, что индукционный нагрев материала КС может быть реализован при воздействии магнитного поля не только на растягивающуюся струю в свободном полете, но и на схлопывающуюся кумулятивную облицовку, если в ней создать аксиальное магнитное поле перед подрывом К3 [25,26]. При этом для получения заметного нагрева КС требуется создание в облицовке гораздо более слабого начального магнитного поля по сравнению с полем, воздействующим на КС в свободном полете, так как облицовка в процессе схлопывания сама генерирует сильное магнитное поле в области струеобразования (эффект магнитокумулятивного генератора) [27]. Однако необходимо иметь в виду, что на КС с усилившимся магнитным полем, выходящую из области струеобразования, действуют мощные растягивающие электромагнитные силы, способные привести к ее разрушению с радиальным диспергированием материала $[28,29]$. Подобное явление наблюдалось в экспериментах $[19,30]$ с К3 диаметром $d_{0}=50 \mathrm{~mm}$ при создании в его конической облицовке из меди перед подрывом начального магнитного поля с индукцией в несколько десятых долей тесла, что приводило к резкому снижению глубины пробития КЗ стальной преграды. В [26] было высказано предположение, что при создании в облицовке КЗ более слабого начального магнитного поля можно избежать диспергирования нагретой индукционными токами КС вследствие действия электромагнитных сил и получить прирост пробивного действия КЗ благодаря увеличению предельного удлинения термически разупрочненной струи. Прямое экспериментальное подтверждение выдвинутой гипотезы пока что отсутствует, хотя некоторые косвенные данные экспериментов [24] свидетельствуют в ее пользу, о чем будет сказано несколько слов ниже.

\section{3. Результаты экспериментов с воздействием магнитного поля}

Экспериментальные и теоретические исследования влияния продольного магнитного поля на растягивающуюся КС в свободном полете проводились в МГТУ им. Н.Э. Баумана с начала 90-х годов прошлого века [21]. Реализация подобного воздействия на КС осуществляется с помощью удлиненного соленоида, распола- 


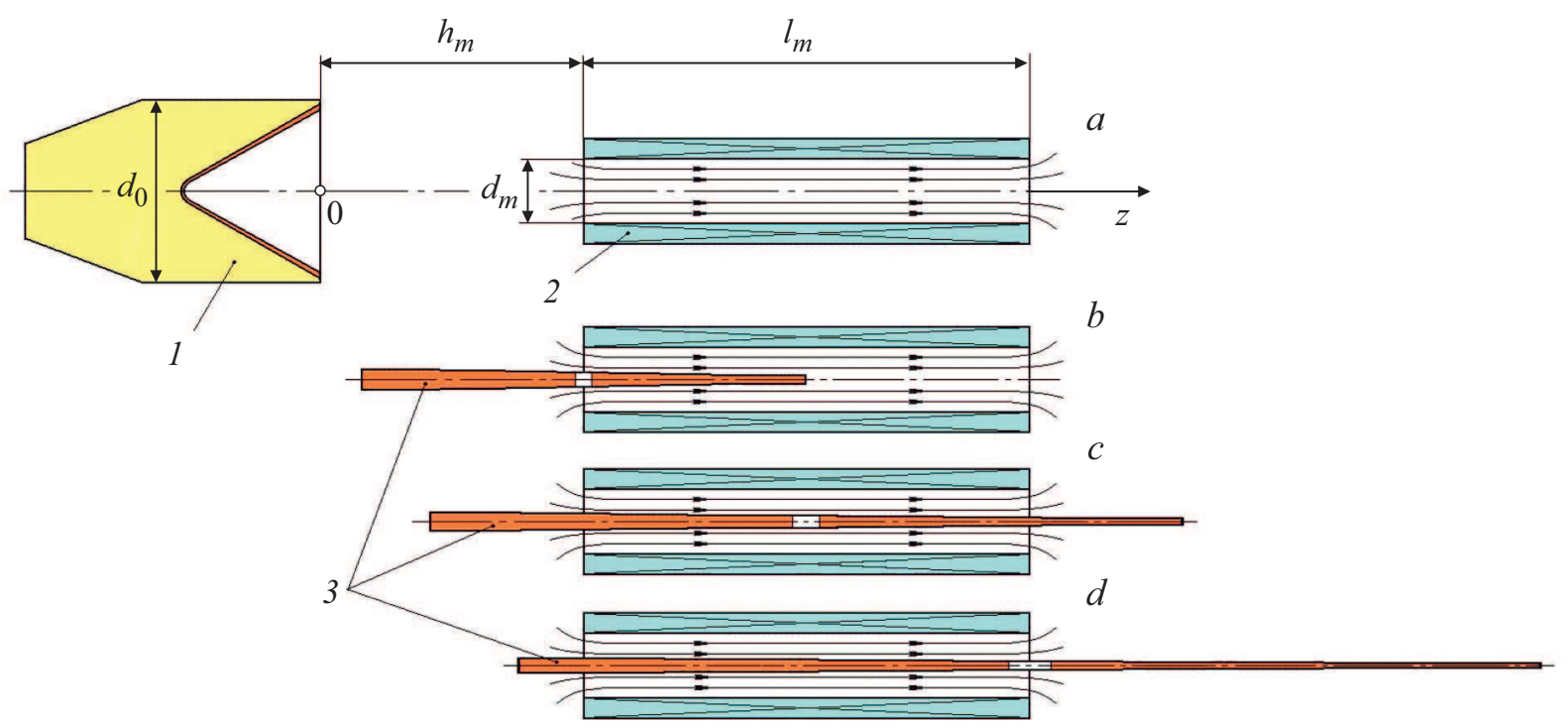

Рис. 2. Воздействие магнитного поля удлиненного соленоида на деформирующуюся КС: $a-$ схема реализации $(1-$ кумулятивный заряд, $2-$ соленоид, 3 - кумулятивная струя), $b-$ вход участка КС в соленоид, $c-$ движение в полости соленоида, $d-$ выход из соленоида.

гаемого перед КЗ и создающего магнитное поле на пути движения струи (рис. 2,a). В экспериментах [21], проводившихся с КЗ диаметром $d_{0}=50 \mathrm{~mm}$, имевшими медную коническую облицовку, при индукции воздействующего на КС поля до $10.5 \mathrm{~T}$ было зафиксировано небольшое увеличение глубины пробития КЗ стальной преграды, не превышавшее $10 \%$. По результатам позднее проведенных теоретических исследований [31,32] был сделан вывод о том, что на более существенное увеличение пробивного действия КЗ можно рассчитывать, если индукция воздействующего на КС поля составляет несколько десятков тесла.

В последнее время интерес к проблеме увеличения пробивного действия КЗ за счет воздействия на КС магнитного поля удлиненного соленоида проявили китайские специалисты [23,24,33-36]. В их экспериментах с КЗ диаметром $d_{0}=56 \mathrm{~mm}$ с медной конической облицовкой воздействие продольного магнитного поля с максимальным значением индукции до 1.7 Т осуществлялось как на деформирующуюся КС при размещении соленоида в ближней от К3 зоне [24], так и на уже разорвавшуюся КС при размещении соленоида на значительном удалении от К3 [23]. В обоих случаях был зафиксирован значительный прирост пробивного действия КЗ на уровне 70\%. Если в случае воздействия на разорванную КС этот прирост связывается авторами [23] с уменьшением при движении в магнитном поле скорости бокового дрейфа элементов распавшейся струи, всегда существующего вследствие наличия асимметрий в К3 [37,38], то увеличение пробития КЗ при воздействии магнитного поля на растягивающуюся КС в ближней от заряда зоне объясняется в [24] именно увеличением предельного удлинения струи, подтверждением чего являются полу- ченные авторами [24] рентгенограммы КС в отсутствие и при реализации электромагнитного воздействия.

Вопросы вызывает большая разница в приросте пробивного действия КЗ при воздействии магнитного поля на деформирующуюся КС, зафиксированном в экспериментах [24] с индукцией поля соленоида всего лишь до $1.7 \mathrm{~T}$ и в ранее проведенных аналогичных экспериментах [21] с индукцией поля соленоида до $10.5 \mathrm{~T}$. Возможно, эта разница связана с тем, что в экспериментах [24] применялись соленоиды существенно большего диаметра, чем в [21]. Он был примерно равен диаметру К3, в то время как в [21] составлял менее одной трети диаметра КЗ. За счет увеличенного диаметра соленоидов, размещавшихся на небольшом расстоянии от основания КЗ с кумулятивной выемкой (также примерно равном диаметру КЗ), область создаваемого такими соленоидами магнитного поля распространялась в экспериментах [24] и на часть К3 с кумулятивной облицовкой. В результате по оценкам [39] при создании магнитного поля с индукцией 1.7 Т на пути движения КС индукция попутно создававшегося поля у основания облицовки составляла в экспериментах [24] около 0.1 T, что примерно втрое больше индукции поля, генерировавшегося у основания облицовки в экспериментах [21] при индукции поля в центре соленоида $10.5 \mathrm{~T}$. Отсюда следует, что полученный в экспериментах [24] значительный прирост пробивного действия КЗ может быть связан не с воздействием магнитного поля на растягивающуюся КС, а с присутствием поля в облицовке КЗ в момент подрыва [39], так как индукция этого поля хорошо согласовалась в этих экспериментах со значениями, при которых, согласно данным [26], как указывалось выше, отрицательное влияние поля в облицовке на пробитие КЗ может смениться положительным. 


\section{4. Задачи исследования}

С целью подтверждения полученных ранее оценок параметров магнитных полей, при которых воздействие поля может существенно повлиять на процесс деформирования КС в свободном полете [31,32], и дополнительного обоснования выдвинутой в [39] гипотезы об истинной причине зафиксированного в экспериментах [24] эффекта повышения пробивного действия КЗ был проведен теоретический анализ поведения растягивающейся КС в магнитном поле удлиненного соленоида. Поводом для проведения такого анализа послужила также необходимость устранения неточностей в представлениях об эволюции магнитного поля соленоида в материале деформирующейся КС, допущенных в ряде последних публикаций по рассматриваемой тематике. В частности, в работе [34] при определении индукционных токов, возникающих в материале участка КС при его входе в полость соленоида, некорректно предполагалось, что индукция поля внутри струи совпадает с индукцией внешнего поля соленоида. То же предположение о равенстве магнитных индукций поля внутри деформирующейся КС и внешнего поля использовалось в работе [35] при анализе влияния магнитного поля на радиальное движение материала струи. Достоинством представляемого теоретического анализа является его базирование на аналитическом описании эволюции магнитного поля соленоида в растягивающейся КС, которое было получено при ряде упрощающих допущений. Это дает возможность простой проверки и использования полученных результатов заинтересованными специалистами.

\section{5. Физико-математическая модель}

В экспериментах [21,24] ближняя граница области воздействия магнитного поля на КС находилась на расстоянии $h_{m}=(1.0-1.5) d_{0}$ от К3 (рис. 2,a), где КС деформируется еще устойчиво с сохранением близкой к цилиндрической формы (без появления „шеек“). Процесс деформирования КС на этой стадии хорошо описывается в рамках модели равномерно удлиняющегося цилиндрического стержня из несжимаемого жесткопластического материала [10]. В каждом поперечном сечении такого стержня радиальная скорость $v_{r}$ движения его материала к оси распределена линейно по радиальной координате $r$

$$
v_{r}=-\frac{\dot{\varepsilon}_{z}}{2} r
$$

где $\dot{\varepsilon}_{z}-$ текущее значение осевой скорости деформирования. Величина $\dot{\varepsilon}_{z}$ и текущий радиус стержня $R$ изменяются с течением времени $t$ по законам

$$
\dot{\varepsilon}_{z}=\frac{\dot{\varepsilon}_{z 0}}{1+\dot{\varepsilon}_{z 0} t}, \quad R=\frac{R_{0}}{\sqrt{1+\dot{\varepsilon}_{z 0} t}},
$$

где $\dot{\varepsilon}_{z 0}, R_{0}-$ соответственно начальная осевая скорость деформирования участка КС и его начальный радиус в момент формирования при схлопывании облицовки.

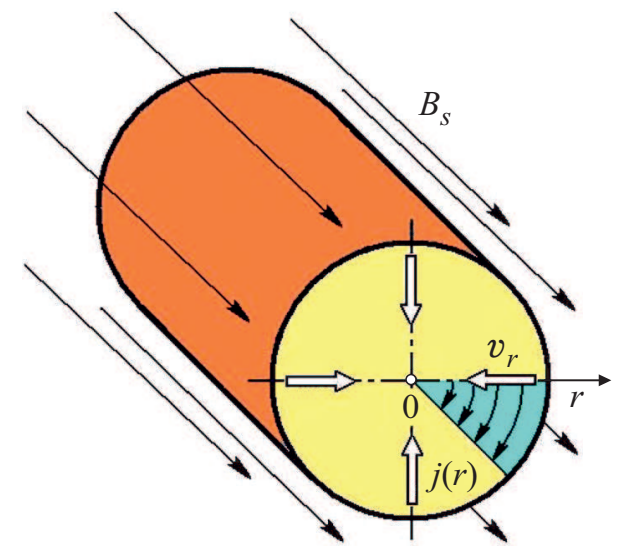

Рис. 3. Расчетная схема для определения эволюции магнитного поля в участке КС.

При входе участка КС в магнитное поле соленоида (рис. 2,b) оно начинает диффундировать в материал участка, приводя к появлению в нем магнитного поля осевой ориентации с индукцией $B$. При этом в материале участка возникает азимутальное электрическое поле с напряженностью $E$ и индуцируются азимутальные вихревые токи с плотностью $j$ (рис. 3). Эволюция электрического и магнитного полей в стержне, моделирующем участок КС, описывается в процессе его удлинения в рамках одномерной осесимметричной задачи магнитной гидродинамики системой соотношений [40], выражающих в дифференциальной форме закон электромагнитной индукции

$$
\frac{d B}{d t}=\dot{\varepsilon}_{z} B-\frac{1}{r} \frac{\partial(E r)}{\partial r},
$$

закон полного тока

$$
j=-\frac{1}{\mu_{0}} \frac{\partial B}{\partial r}
$$

и закон Ома

$$
E=\eta j,
$$

где $\mu_{0}=4 \pi \cdot 10^{-7} \mathrm{H} / \mathrm{m}$ - магнитная постоянная, $\eta$ удельное сопротивление материала стержня. Отметим, что первое слагаемое в правой части закона электромагнитной индукции (3) „ответственно“ за генерацию магнитного поля в растягивающемся стержне, обусловленную непрерывным уменьшением площади его сечения, а второе - за диффузию поля. Граничные условия для определения на основании соотношений (3)-(5) эволюции магнитного поля в стержне, формулируемые на его оси $(r=0)$ и поверхности $(r=R)$, являются следующими:

$$
\left.\frac{\partial B}{\partial r}\right|_{r=0}=0, \quad B(R, t)=B_{s}(t),
$$

где $B_{s}(t)$ - закон изменения продольной компоненты магнитного поля соленоида на поверхности участка КС 
(рис. 3), связанный с движением струи. Начальное условие для индукции магнитного поля в стержне является нулевым

$$
B(r, 0)=0 .
$$

Как было замечено в [31], результаты проведенного в [21] численного решения задачи (2)-(7) об эволюции магнитного поля соленоида в растягивающейся КС хорошо согласуются с результатами решения той же задачи в предположении линейности в любой момент времени распределения плотности азимутальных индукционных токов в стержне по радиальной координате $r$

$$
j(r, t)=\varphi(t) r
$$

где $\varphi(t)$ - коэффициент, зависящий только от времени. Отметим, что данное допущение с учетом (4) обеспечивает автоматическое выполнение граничного условия (6) для индукции магнитного поля на оси стержня $(r=0)$.

Принимая в расчетной модели для определения эволюции магнитного поля в стержне допущение (8) о линейности радиального распределения индукционных токов, получим радиальное распределение магнитной индукции в стержне, имеющее в любой момент времени параболический вид

$$
B(r, t)=\mu_{0} \int_{r}^{R} j(r, t) d t+B_{s}(t)=\frac{\mu_{0} \varphi(t)}{2}\left(R^{2}-r^{2}\right)+B_{s}(t) .
$$

Индукция магнитного поля на оси стержня определится, как

$$
B_{c}(t)=B(0, t)=\frac{\mu_{0} \varphi(t) R^{2}}{2}+B_{s}(t),
$$

с учетом чего выражение для индукции поля в стержне может быть переписано в виде

$$
B(r, t)=B_{c}(t)+\left(B_{s}(t)-B_{c}(t)\right) \frac{r^{2}}{R^{2}} .
$$

Для определения эволюции магнитной индукции $B_{c}$ на оси стержня (которая в рамках принятого допущения определяет распределение поля по всему сечению стержня) воспользуемся уравнением (3), записывая его для частиц на оси стержня $(r=0)$. Представляя напряженность электрического поля $E$ в (3), согласно (5) и $(8)$, как $E=\eta \varphi(t) r$, и учитывая, что в соответствии c (9)

$$
\varphi(t)=\frac{2}{\mu_{0} R^{2}}\left(B_{c}(t)-B_{s}(t)\right),
$$

при дополнительном предположении о постоянстве удельного сопротивления $\eta$ материала стержня получим

$$
\frac{d B_{c}}{d t}-B_{c}\left(\dot{\varepsilon}_{z}-\frac{4 \eta}{\mu_{0} R^{2}}\right)=\frac{4 \eta}{\mu_{0} R^{2}} B_{s}(t),
$$

где параметры стержня $\dot{\varepsilon}_{z}$ и $R$ изменяются в зависимости от времени согласно соотношениям (2).

\section{6. Решение для недеформирующегося стержня}

Применим сначала записанное дифференциальное уравнение (12) для определения эволюции магнитного поля в недеформирующемся стержне $\left(\dot{\varepsilon}_{z}=0\right)$ неизменного радиуса $R=R_{0}$ :

$$
\frac{d B_{c}}{d t}+\frac{4 \eta}{\mu_{0} R_{0}^{2}} B_{c}=\frac{4 \eta}{\mu_{0} R_{0}^{2}} B_{s}(t) .
$$

В случаях, когда недеформирующийся стержень с изначально отсутствующим в нем полем $\left(B_{c}(0)=0\right)$ помещается во внешнее постоянное магнитное поле с индукцией $B_{s}(t)=B_{0}$ и когда, напротив, в таком стержне в начальный момент времени присутствует магнитное поле с индукцией $B_{c}(0)=B_{0}$, а поля снаружи стержня нет $\left(B_{s}(t)=0\right)$, решения уравнения (13) представляются соответственно выражениями

$$
B_{c}(t)=B_{0}\left(1-\exp \left(-t / \tau_{0}\right)\right), B_{c}(t)=B_{0} \exp \left(-t / \tau_{0}\right),
$$

где $\tau_{0}-$ постоянная времени диффузии поля, определяемая как

$$
\tau_{0}=\frac{\mu_{0} R_{0}^{2}}{4 \eta} .
$$

Указанные две задачи диффузии магнитного поля в проводящем стержне имеют точные аналитические решения, получаемые методами математической физики [41] и представляемые соответственно соотношениями

$$
\begin{gathered}
B(r, t)=B_{0}\left\{1-2 \sum_{k=1}^{\infty} \frac{J_{0}\left(v_{k} r / R_{0}\right)}{v_{k} J_{1}\left(v_{k}\right)} \exp \left(-\frac{v_{k}^{2} \eta}{\mu_{0} R_{0}^{2}} t\right)\right\}, \\
B(r, t)=2 B_{0} \sum_{k=1}^{\infty} \frac{J_{0}\left(v_{k} r / R_{0}\right)}{v_{k} J_{1}\left(v_{k}\right)} \exp \left(-\frac{v_{k}^{2} \eta}{\mu_{0} R_{0}^{2}} t\right),
\end{gathered}
$$

где $J_{0}, J_{1}-$ функции Бесселя первого рода соответственно нулевого и первого порядков [42], $v_{k}-$ положительные корни уравнения $J_{0}(v)=0$.

Из рис. 4, где проиллюстрировано изменение магнитной индукции на оси стержня неизменного радиуса в рассмотренных задачах диффузии магнитного поля, видно, что между результатами приближенных аналитических решений (14), основанных на предположении о линейности радиального распределения индукционных токов, и точных решений, следующих из (16) при $r=0$, наблюдается хорошее соответствие. Это дает основания полагать предложенную упрощенную модель пригодной для описания эволюции магнитного поля в КС при ее движении через полость соленоида.

\section{7. Растяжение струи в полости соленоида}

Рассмотрим сначала электромагнитные процессы в участке КС при его входе в полость соленоида 


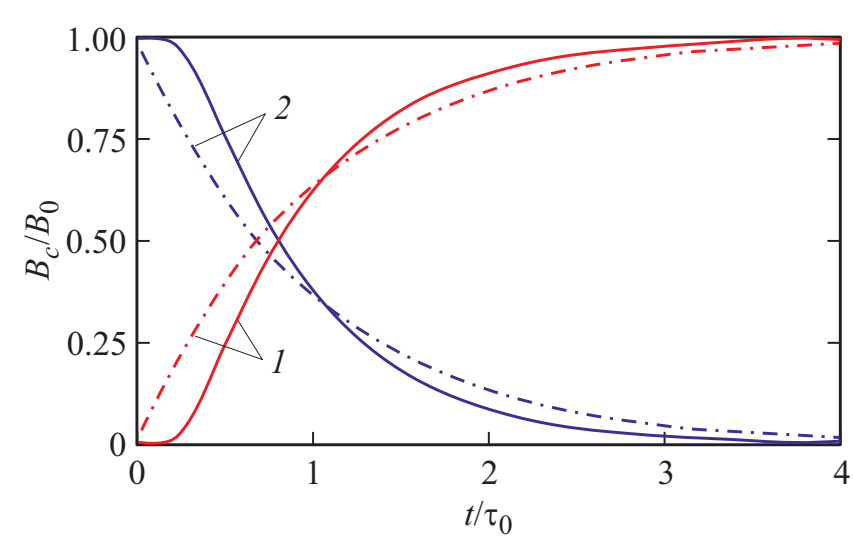

Рис. 4. Изменение магнитной индукции на оси недеформирующегося проводящего стержня в соответствии с точным (сплошные линии) и приближенным (штрихпунктирные линии) аналитическими решениями: 1 - в задаче о проникновении внешнего магнитного поля в стержень, 2 - в задаче об ослаблении изначально существовавшего в стержне магнитного поля в отсутствие поля снаружи.

(рис. $2, b)$. Введя коэффициент удлинения участка струи $n=1+\dot{\varepsilon}_{z 0} t$, характеризующий отношение его текущей длины к начальной, уравнение (12) с учетом соотношений (2) для $\dot{\varepsilon}_{z}$ и $R$ перепишем в виде

$$
\frac{d B_{c}}{d n}-B_{c}\left(\frac{1}{n}-\frac{n}{\operatorname{Re}_{m, 0}}\right)=\frac{n}{\operatorname{Re}_{m, 0}} B_{s}(n),
$$

где $\operatorname{Re}_{m, 0}$ - магнитное число Рейнольдса, представляемое с использованием начальных значений скорости деформирования $\dot{\varepsilon}_{z 0}$ и радиуса $R_{0}$ участка КС, как

$$
\operatorname{Re}_{m, 0}=\frac{\mu_{0} \dot{\varepsilon}_{z 0} R_{0}^{2}}{4 \eta}
$$

Значение $\operatorname{Re}_{m, 0}$ характеризует соотношение темпов генерации магнитного поля, определяемого скоростью деформирования $\dot{\varepsilon}_{z 0}$, и его диффузии, определяемого временем диффузии $\tau_{0}(15)$, в участке КС на момент его формирования $\operatorname{Re}_{m, 0}=\dot{\varepsilon}_{z 0} \tau_{0}$. С учетом (2) в процессе растяжения участка КС магнитное число Рейнольдса для него уменьшается обратно пропорционально квадрату текущего коэффициента удлинения $\operatorname{Re}_{m}=\operatorname{Re}_{m, 0} / n^{2}$.

Для удлиненных соленоидов с длиной $l_{m}$, существенно превышающей их диаметр $d_{m}$ (рис. $\left.2, a\right)$, длины участков нарастания индукции магнитного поля на входе в полость соленоида и последующего ее спада на выходе из соленоида, определяемые диаметром $d_{m}$, относительно невелики в сравнении с длиной соленоида $l_{m}$. Это позволяет идеализировать распределение магнитной индукции на оси КЗ вдоль пути движения струи, полагая ее равномерно распределенной с неизменным значением $B_{0}$ на участке длиной $l_{m}$ внутри соленоида и равной нулю за пределами этого участка.

При такой идеализации эволюция магнитного поля в элементе КС при его входе в полость соленоида будет описываться решением уравнения (17) с индукцией поля соленоида в правой части $B_{s}(n)=B_{0}$ при начальном условии $B_{c}\left(n_{b}\right)=0$, где $n_{b}=1+\dot{\varepsilon}_{z 0} t_{b}-$ коэффициент удлинения элемента КС на момент времени $t_{b}$, соответствующий входу в соленоид и определяемый с использованием значений скорости элемента $v_{j}$, координаты относительно основания КЗ точки его формирования на оси заряда при схлопывании облицовки $z_{f}$ и расстояния от КЗ до соленоида $h_{m}$ (рис. 2,a), как

$$
t_{b}=\frac{h_{m}-z_{f}}{v_{j}} \text {. }
$$

Указанное решение, предполагающее длину соленоида неограниченной, представляется в виде

$$
\begin{aligned}
& B_{c}=B_{0} \sqrt{\frac{2}{\operatorname{Re}_{m, 0}}} n\left[F\left(\frac{n}{\sqrt{2 \mathrm{Re}_{m, 0}}}\right)-F\left(\frac{n_{b}}{\sqrt{2 \mathrm{Re}_{m, 0}}}\right)\right. \\
& \left.\times \exp \left(-\frac{n^{2}-n_{b}^{2}}{2 \operatorname{Re}_{m, 0}}\right)\right] \text {, }
\end{aligned}
$$

где $F(x)=\exp \left(-x^{2}\right) \int_{0}^{x} \exp \left(y^{2}\right) d y$ - интеграл Доусона [42], $n \geq n_{b}$. Для анализа представленное решение удобно переписать, введя в него относительный коэффициент удлинения участка КС $n_{r b}$, отсчитываемый от момента его входа в соленоид $n_{r b}=n / n_{b} \geq 1$

$$
\begin{aligned}
B_{c}= & B_{0} \sqrt{\frac{2}{\operatorname{Re}_{m, b}}} n_{r b}\left[F\left(\frac{n_{r b}}{\sqrt{2 \mathrm{Re}_{m, b}}}\right)-F\left(\frac{1}{\sqrt{2 \mathrm{Re}_{m, b}}}\right)\right. \\
& \left.\times \exp \left(-\frac{n_{r b}^{2}-1}{2 \operatorname{Re}_{m, b}}\right)\right],
\end{aligned}
$$

где $\operatorname{Re}_{m, b}=\operatorname{Re}_{m, 0} / n_{b}^{2}$ - магнитное число Рейнольдса на момент входа в соленоид. Для медных высокоградиентных КС при диаметрах КЗ $d_{0}$ от 30 до $150 \mathrm{~mm}$ возможные значения $\operatorname{Re}_{m, b}$ укладываются примерно в диапазон $0.1<\operatorname{Re}_{m, b}<100$.

На рис. 5 проиллюстрировано изменение магнитной индукции на оси участка КС после его входа в соленоид в зависимости от отсчитываемого от этого момента коэффициента удлинения $n_{r b}$ при различных значениях $\mathrm{Re}_{m, b}$ в предположении неограниченной длины соленоида. Видно, что для всех $\operatorname{Re}_{m, b}$ индукция $B_{c}$, возрастая от нулевого значения, достигает точки максимума, в которой превышает индукцию поля соленоида $B_{0}$, а затем уменьшается, асимптотически стремясь к значению $B_{0}$. C увеличением $\operatorname{Re}_{m, b}$ достижение максимума индукции поля в участке КС отодвигается на более поздние моменты времени с одновременным возрастанием значения $B_{c, \max }$ в максимуме.

Реперными для кривых изменения индукции магнитного поля на оси участка КС (рис. 5) являются точки, в которых она сравнивается с индукцией внешнего поля соленоида $B_{0}$ и достигает максимального значения. Относительный коэффициент удлинения участка КС 


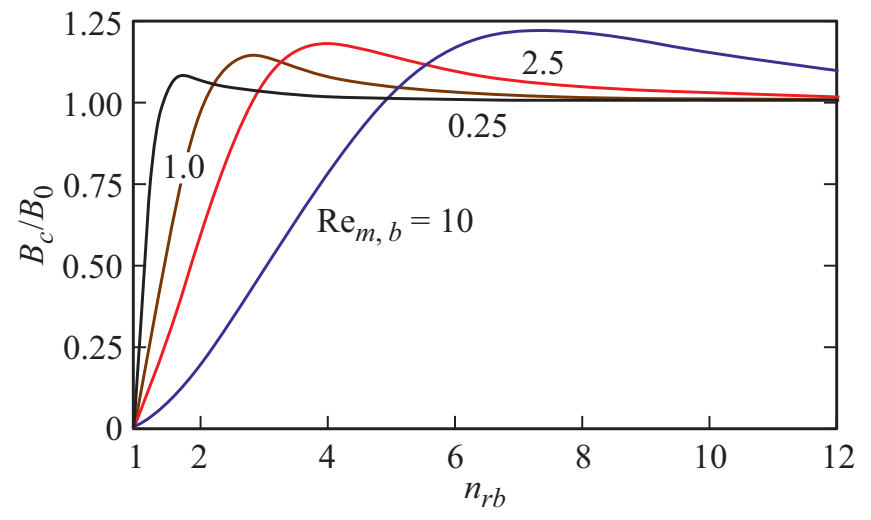

Рис. 5. Изменение магнитной индукции на оси участка КС при его движении в полости соленоида.

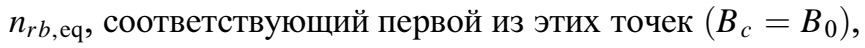
определяется из уравнения

$$
\begin{aligned}
& \sqrt{\frac{2}{\operatorname{Re}_{m, b}}} n_{r b, \text { eq }}\left[F\left(\frac{n_{r b, \mathrm{eq}}}{\sqrt{2 \mathrm{Re}_{m, b}}}\right)-F\left(\frac{1}{\sqrt{2 \mathrm{Re}_{m, b}}}\right)\right. \\
& \left.\quad \times \exp \left(-\frac{n_{r b, \mathrm{eq}}^{2}-1}{2 \operatorname{Re}_{m, b}}\right)\right]-1=0 .
\end{aligned}
$$

Уравнение для определения относительного коэффициента удлинения участка КС $n_{r b \text { max }}$, соответствующего максимуму индукции поля в нем, получается из условия равенства нулю производной решения (20) по переменной $n_{r b}$

$$
\begin{aligned}
& \frac{n_{r b, \max }}{\sqrt{2 \mathrm{Re}_{m, b}}}+\left(1-\frac{n_{r b, \text { max }}^{2}}{\operatorname{Re}_{m, b}}\right)\left[F\left(\frac{n_{r b, \max }}{\sqrt{2 \mathrm{Re}_{m, b}}}\right)\right. \\
& \left.-F\left(\frac{1}{\sqrt{2 \mathrm{Re}_{m, b}}}\right) \exp \left(-\frac{n_{r b, \max }^{2}-1}{2 \mathrm{Re}_{m, b}}\right)\right]=0,
\end{aligned}
$$

вычисляемой с использованием для интеграла Доусона тождества [42]

$$
\frac{d F}{d x}=1-2 x F(x) .
$$

На основании численного решения приведенных уравнений рассчитывались значения $n_{r b \text {, еq }}$ и $n_{r b, \max }$, с использованием которых были определены отнесенные к постоянной времени диффузии поля $\tau_{b}=\tau_{0} / n_{b}$ на момент входа участка КС в соленоид и отсчитываемые от этого момента промежутки времени

$$
\frac{t_{r b, \mathrm{eq}}}{\tau_{b}}=\frac{n_{r b, \mathrm{eq}}-1}{\mathrm{Re}_{m, b}}, \quad \frac{t_{r b, \text { max }}}{\tau_{b}}=\frac{n_{r b, \max }-1}{\operatorname{Re}_{m, b}},
$$

спустя которые индукция магнитного поля $B_{c}$ на оси участка КС соответственно сравнивалась с индукцией поля соленоида и достигала максимального значения $B_{c, \max }$. Полученные для отношений $t_{r b, \mathrm{eq}} / \tau_{b}, t_{r b, \max } / \tau_{b}$, a также для отношения $B_{c, \max } / B_{0}$, определявшегося из (20) при $n_{r b}=n_{r b, \max }$, результаты показаны на рис. 6 сплошными линиями в зависимости от магнитного числа Рейнольдса $\mathrm{Re}_{m, b}$ на момент входа участка КС в соленоид. Пунктирными линиями на этом рисунке приводятся построенные для зависимостей $t_{r b, \mathrm{eq}} / \tau_{b}$ и $t_{r b, \max } / \tau_{b}$ от $\operatorname{Re}_{m, b}$ аппроксимации в диапазоне $0.1<\operatorname{Re}_{m, b}<100$

$$
\frac{t_{r b, \mathrm{eq}}}{\tau_{b}}=\mathrm{Re}_{m, b}^{-0.43}, \quad \frac{t_{r b, \max }}{\tau_{b}}=1.7 \mathrm{Re}_{m, b}^{-0.44},
$$

из которых следует, что время достижения максимума индукции магнитного поля в элементе КС $t_{r b, \max }$ после его входа в полость соленоида примерно на 70\% превышает время выравнивания индукций внутреннего

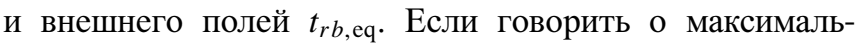
ном усилении магнитного поля на оси участка КС, то оно изменяется от $B_{c, \max } / B_{0} \approx 1.050$ при $\operatorname{Re}_{m, b}=0.1$ до $B_{c, \max } / B_{0} \approx 1.264$ при $\operatorname{Re}_{m, b}=100$ (рис. 6). Столь незначительный рост достигаемого максимума индукции поля в струе при значительном увеличении магнитного числа Рейнольдса (в 1000 раз) обусловлен конкуренцией двух факторов. С одной стороны, замедление диффузии поля, происходящее с увеличением значения $\mathrm{Re}_{m, b}$, способствует ускорению его генерации в струе, но, c другой стороны, эта генерация становится возможной только после проникновения в струю внешнего поля, чему препятствует рост $\operatorname{Re}_{m, b}$.

Еще раз отметим, что решение (19) уравнения (17) для эволюции магнитного поля в участке КС и все полученные выше на его основании результаты относятся к случаю соленоида неограниченной длины. Очевидно, для соленоидов конечной длины индукция магнитного поля в элементе КС при определенных условиях может не успеть сравняться с индукцией поля соленоида или достичь своего максимально возможного значения $B_{c, \max }$ до выхода элемента струи из полости соленоида. Если ввести в рассмотрение координату участка КС относительно точки входа в соленоид $z_{r b}=z-h_{m} \geq 0$

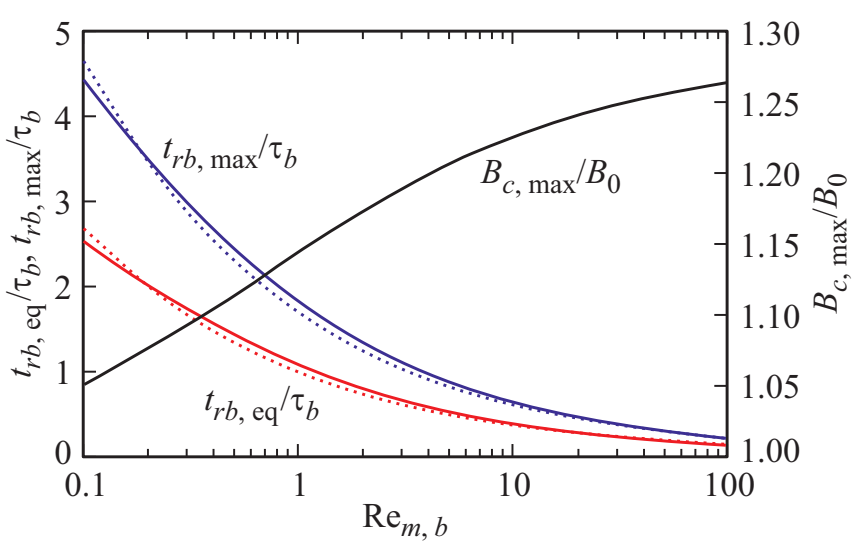

Рис. 6. Зависимости относительных времен достижения магнитной индукцией на оси участка КС, движущегося в полости соленоида, индукции внешнего поля и максимального значения, а также относительного значения индукции поля на оси в максимуме от магнитного числа Рейнольдса на момент входа участка струи в соленоид. 
и представить относительный коэффициент удлинения участка $n_{r b}$ в решении (20), как

$$
n_{r b}=1+\frac{\dot{\varepsilon}_{z 0}}{n_{b}} \frac{z_{r b}}{v_{j}},
$$

можно получить описание эволюции магнитного поля в движущемся в полости соленоида участке струи (рис. 2,c) в зависимости от его текущего положения относительно соленоида. Для определения координат элемента КС относительно точки входа в соленоид, соответствующих равенству магнитной индукции на его оси

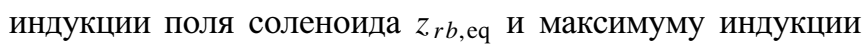

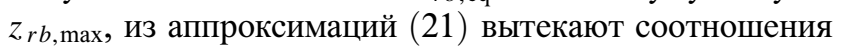

$$
\frac{z_{r b, \mathrm{eq}}}{v_{j} \tau_{b}}=\mathrm{Re}_{m, b}^{-0.43}, \quad \frac{z_{r b, \max }}{v_{j} \tau_{b}}=1.7 \mathrm{Re}_{m, b}^{-0.44} .
$$

Из сравнения значений $z_{r b, \text { eq }}$ и $z_{r b, \max }$ с длиной соленоида $l_{m}$ можно установить, на какой стадии эволюции магнитного поля в участке КС он покидает соленоид.

\section{8. Растяжение струи после выхода из соленоида}

Учтем конечность длины соленоида и рассмотрим электромагнитные процессы в участке КС при его выходе из полости соленоида (рис. 2,d). В рамках рассматриваемой идеализации поля соленоида с мгновенным уменьшением его индукции от постоянного значения $B_{0}$ до нуля в момент выхода участка КС за пределы полости соленоида изменение магнитной индукции на оси участка, вышедшего из соленоида, будет описываться решением уравнения (17) с нулевой правой частью при начальном условии $B_{c}\left(n_{e}\right)=B_{c e}$, где $n_{e}=1+\dot{\varepsilon}_{z 0} t_{e}-$ коэффициент удлинения участка струи на момент времени $t_{e}$, соответствующий выходу из соленоида и определяемый, как

$$
t_{e}=\frac{h_{m}+l_{m}-z_{f}}{v_{j}},
$$

a $B_{c e}$ - магнитная индукция на оси участка в этот момент. Указанное решение при $n \geq n_{e}$ представляется в виде

$$
B_{c}=B_{c e} \frac{n}{n_{e}} \exp \left(-\frac{n^{2}-n_{e}^{2}}{2 \operatorname{Re}_{m, 0}}\right),
$$

входящее в него значение $B_{c e}$ рассчитывается на основании соотношения (20) при подстановке в него $n_{r b}=n_{e} / n_{b}$. Так же, как и при анализе эволюции магнитного поля в участке КС при его входе в соленоид, представленное решение удобно переписать, введя в него относительный коэффициент удлинения участка $n_{r e}$, отсчитываемый от момента его выхода из соленоида $n_{r e}=n / n_{e} \geq 1$ :

$$
B_{c}=B_{c e} n_{r e} \exp \left(-\frac{n_{r e}^{2}-1}{2 \operatorname{Re}_{m, e}}\right),
$$

где $\operatorname{Re}_{m, e}=\operatorname{Re}_{m, 0} / n_{e}^{2}$ - магнитное число Рейнольдса на момент выхода из соленоида.

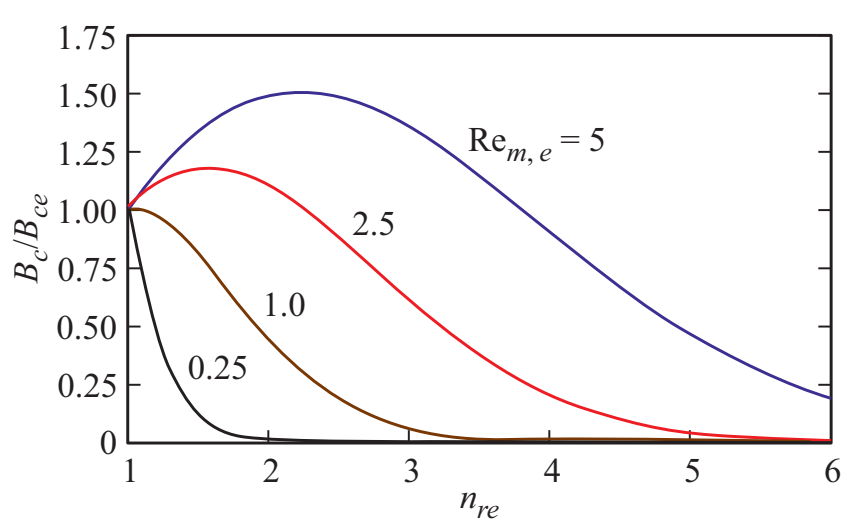

Рис. 7. Изменение магнитной индукции на оси участка КС после его выхода из соленоида.

Дифференцируя записанное решение (23) по $n_{r e}$

$$
\frac{d B_{c}}{d n_{r e}}=B_{c e}\left(1-\frac{n_{r e}^{2}}{\operatorname{Re}_{m, e}}\right) \exp \left(-\frac{n_{r e}^{2}-1}{2 \operatorname{Re}_{m, e}}\right),
$$

можно установить, что характер поведения поля в растягивающемся участке КС после его выхода из соленоида зависит от значения параметра $\operatorname{Re}_{m, e}$. При $\operatorname{Re}_{m, e} \leq 1$ скорость диффузионных процессов в момент выхода высока (выше темпа генерации поля), и индукция поля в участке КС монотонно убывает. При $\operatorname{Re}_{m, e}>1$, напротив, сразу после выхода из соленоида темп генерации поля в участке КС превышает темп его диффузионного „рассасывания“ и поэтому убыванию интенсивности поля предшествует стадия ее дополнительного нарастания (рис. 7). Максимум индукции поля на оси участка КС, вышедшего из соленоида при $\mathrm{Re}_{m, e}>1$, достигается при относительном коэффициенте удлинения $n_{r e, \max }=\sqrt{\mathrm{Re}_{m, e}}$ и составляет

$$
B_{c e, \text { max }}=B_{c e} \sqrt{\operatorname{Re}_{m, e}} \exp \left(-\frac{\operatorname{Re}_{m, e}-1}{2 \operatorname{Re}_{m, e}}\right) .
$$

На рис. 8 проиллюстрировано изменение отнесенного к постоянной времени диффузии поля $\tau_{e}=\tau_{0} / n_{e}$ на момент выхода участка КС из соленоида и отсчитываемого от этого момента промежутка времени

$$
\frac{t_{r e, \max }}{\tau_{e}}=\frac{n_{r e, \max }-1}{\operatorname{Re}_{m, e}}=\frac{\sqrt{\operatorname{Re}_{m, e}}-1}{\operatorname{Re}_{m, e}},
$$

спустя который индукция магнитного поля $B_{c}$ на оси участка КС достигает максимального значения, и самого этого значения, отнесенного к индукции поля на оси участка в момент выхода из соленоида $B_{c e, \max } / B_{c e}$, в зависимости от магнитного числа Рейнольдса $\operatorname{Re}_{m, e}$ на тот же момент (при $\mathrm{Re}_{m, e}>1$ ).

\section{9. Индукционный нагрев струи}

Оценим на основании представленной модели эволюции магнитного поля удлиненного соленоида в деформирующейся КС возможность стабилизации ее растяжения 


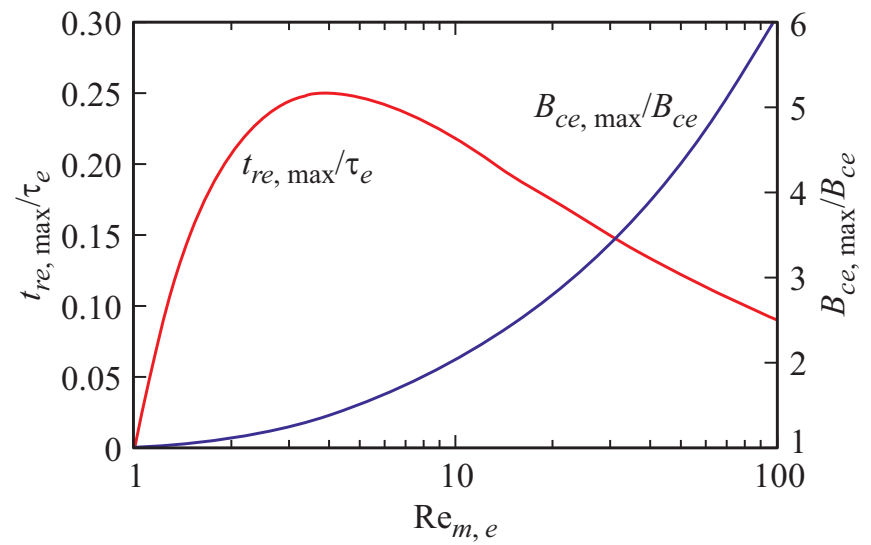

Рис. 8. Зависимости относительного времени достижения магнитной индукцией на оси участка КС, вышедшего из соленоида, максимального значения, а также относительного значения индукции поля на оси в максимуме от магнитного числа Рейнольдса на момент выхода при $\mathrm{Re}_{m, e}>1$.

с увеличением предельного удлинения. Как отмечалось выше, стабилизирующее влияние магнитного поля на процесс растяжения КС может быть связано с термическим разупрочнением материала струи и с дополнительным силовым воздействием на струю. Поэтому определим температуру нагрева КС и действующие в ней механические напряжения при деформировании в магнитном поле соленоида.

Нагрев материала КС при воздействии магнитного поля обусловлен выделением в нем джоулева тепла за счет циркуляции в струе вихревых индукционных токов. Повышение температуры КС $T_{J}$ вследствие джоулева нагрева описывается уравнением

$$
\rho c \frac{d T_{J}}{d t}=j^{2} \eta
$$

где $\rho$ и $c-$ соответственно плотность и удельная теплоемкость материала КС. В соответствии с (8) наиболее интенсивно будет нагреваться поверхностный слой струи, где плотность индукционных токов максимальна.

Для температуры джоулева нагрева поверхности КС $T_{J, R}$, где, согласно (8) и (11):

$$
j(R, t)=\frac{2}{\mu_{0} R}\left(B_{c}(t)-B_{s}(t)\right),
$$

на стадии движения участка КС в полости соленоида $n_{b} \leq n \leq n_{e}$, для которой $B_{s}=B_{0}$, а $B_{c}$ представляется соотношением (19), решение уравнения (24) после перехода от времени $t$ к коэффициенту удлинения $n$ дается интегралом

$$
\begin{aligned}
T_{J, R}= & \frac{4 T_{J, \mathrm{ch}}}{\operatorname{Re}_{m, 0}^{2}} \int_{n_{b}}^{n} v^{3}\left[F\left(\frac{v}{\sqrt{2 \mathrm{Re}_{m, 0}}}\right)-F\left(\frac{n_{b}}{\sqrt{2 \mathrm{Re}_{m, 0}}}\right)\right. \\
& \left.\times \exp \left(-\frac{v^{2}-n_{b}^{2}}{\sqrt{2 \mathrm{Re}_{m, 0}}}\right)-\frac{\sqrt{\mathrm{Re}_{m, 0}}}{\sqrt{2} v}\right]^{2} d v
\end{aligned}
$$

где характеристическая температура

$$
T_{J, \mathrm{ch}}=\frac{B_{0}^{2}}{2 \mu_{0} \rho c}
$$

имеет смысл температуры нагрева материала при выделении в единице его объема теплоты, равной объемной плотности энергии магнитного поля с индукцией $B_{0}$. Интегрирование в соотношении для $T_{J, R}$ при $n_{b} \leq n \leq n_{e}$ удается провести в аналитическом виде с получением в результате зависимости

$$
\begin{aligned}
T_{J, R} & =2 T_{J, \mathrm{ch}}\left[F\left(\frac{n}{\sqrt{2 \mathrm{Re}_{m, 0}}}\right)-F\left(\frac{n_{b}}{\sqrt{2 \mathrm{Re}_{m, 0}}}\right)\right. \\
& \left.\times \exp \left(-\frac{n^{2}-n_{b}^{2}}{\sqrt{2 \mathrm{Re}_{m, 0}}}\right)\right]\left\{\sqrt{\frac{2}{\sqrt{\mathrm{Re}_{m, 0}}}} n-\left(1+\frac{n^{2}}{\mathrm{Re}_{m, 0}}\right)\right. \\
& \times\left[F\left(\frac{n}{\sqrt{2 \mathrm{Re}_{m, 0}}}\right)-F\left(\frac{n_{b}}{\sqrt{2 \mathrm{Re}_{m, 0}}}\right)\right. \\
& \left.\left.\times \exp \left(-\frac{n^{2}-n_{b}^{2}}{\sqrt{2 \mathrm{Re}_{m, 0}}}\right)\right]\right\} .
\end{aligned}
$$

Для стадии движения после выхода из соленоида $n>n_{e}$ интегрирование уравнения (24) с использованием в (25) $B_{s}=0$ и значения $B_{c}$, представляемого соотношением (22), в котором $B_{c e}$ определено из (19) при $n=n_{e}$, приводит к закону изменения температуры джоулева нагрева поверхности КС в виде

$$
\begin{aligned}
T_{J, R}= & T_{J 1, R}+2 T_{J, \mathrm{ch}}\left[F\left(\frac{n_{e}}{\sqrt{2 \mathrm{Re}_{m, 0}}}\right)-F\left(\frac{n_{b}}{\sqrt{2 \mathrm{Re}_{m, 0}}}\right)\right. \\
& \left.\times \exp \left(-\frac{n_{e}^{2}-n_{b}^{2}}{2 \mathrm{Re}_{m, 0}}\right)\right]^{2}\left[\frac{n_{e}^{2}}{\mathrm{Re}_{m, 0}}+1-\left(\frac{n^{2}}{\operatorname{Re}_{m, 0}}+1\right)\right. \\
& \left.\times \exp \left(-\frac{n^{2}-n_{e}^{2}}{\operatorname{Re}_{m, 0}}\right)\right],
\end{aligned}
$$

где $T_{J 1, R}$ - температура поверхности участка струи в момент выхода из соленоида, рассчитываемая по зависимости (27) при $n=n_{e}$.

Результирующая температура джоулева нагрева поверхности участка КС, прошедшего соленоид, определяется из (28) при $n \rightarrow \infty$ и может быть представлена, как

$$
T_{J \Sigma, R}=T_{J 1, R}+T_{J 2, R},
$$

где $T_{J 2, R}$ - предельный прирост температуры поверхности участка отдельно на стадии его движения после выхода из соленоида, являющийся предельным значением второго слагаемого в (28) при $n \rightarrow \infty$

$$
\begin{aligned}
T_{J 2, R}= & 2 T_{J, \mathrm{ch}}\left[F\left(\frac{n_{e}}{\sqrt{2 \mathrm{Re}_{m, 0}}}\right)-F\left(\frac{n_{b}}{\sqrt{2 \mathrm{Re}_{m, 0}}}\right)\right. \\
& \left.\times \exp \left(-\frac{n_{e}^{2}-n_{b}^{2}}{2 \mathrm{Re}_{m, 0}}\right)\right]^{2}\left(\frac{n_{e}^{2}}{\operatorname{Re}_{m, 0}}+1\right) .
\end{aligned}
$$



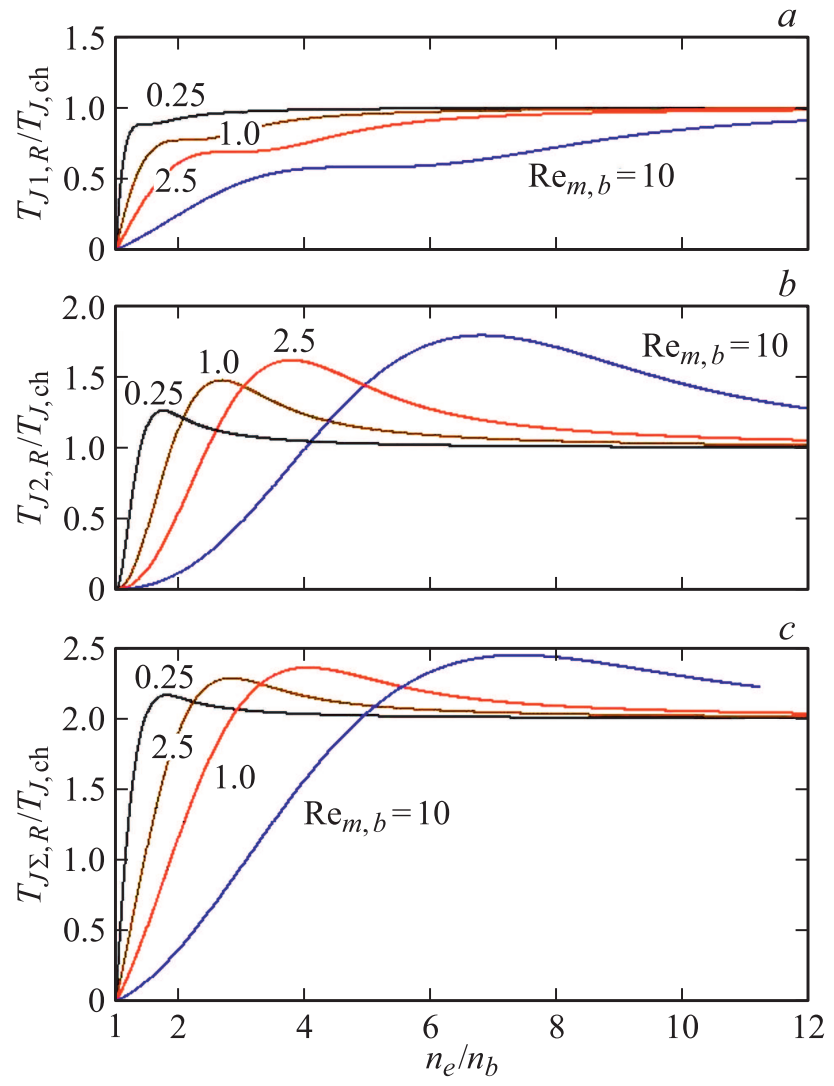

Рис. 9. Влияние на конечную температуру джоулева нагрева поверхности участка КС продолжительности его деформирования в полости соленоида: $a-$ нагрев на стадии движения в полости соленоида, $b-$ дополнительный нагрев после выхода из соленоида, $c-$ результирующий нагрев.

Распределение температуры джоулева нагрева по радиусу КС в соответствии с принятым линейным радиальным распределением плотности индукционных токов (8) и с учетом (24), очевидно, будет иметь во все моменты времени параболический вид

$$
T_{J}(r)=T_{J, R} \frac{r^{2}}{R^{2}}
$$

с уменьшением интенсивности нагрева по мере приближения к оси $(r=0)$, где нагрев отсутствует. Легко установить, что при таком распределении осредненная по сечению струи температура джоулева нагрева составляет половину от ее значения $T_{J, R}$ на поверхности.

Исследуем зависимость результирующего джоулева нагрева поверхности участка КС (29) и его составляющих $T_{J 1, R}, T_{J 2, R}$, от соотношения коэффициентов удлинения участка $n_{e} / n_{b}$ на моменты выхода и входа в соленоид, что фактически означает определение влияния на джоулев нагрев КС длины соленоида $l_{m}$ (рис. 2,a), так как

$$
\frac{n_{e}}{n_{b}}=1+\frac{\dot{\varepsilon}_{z 0}}{n_{b}} \frac{l_{m}}{v_{j}} .
$$

C ростом $n_{e} / n_{b}$ (длины соленоида $l_{m}$ ) отношение $T_{J 1, R} / T_{J, \mathrm{ch}}$, характеризующее джоулев нагрев КС на первой стадии (стадии движения в полости соленоида), монотонно возрастает, стремясь к единице (рис. 9, $a$ ). К единичному значению для соленоидов большой длины $\left(n_{e} / n_{b} \rightarrow \infty\right)$ стремится и отношение $T_{J 2, R} / T_{J, \text { ch }}$, характеризующее нагрев КС на второй стадии (стадии движения после выхода из соленоида). Однако в отличие от $T_{J 1, R} / T_{J, \mathrm{ch}}$, эволюция отношения $T_{J 2, R} / T_{J, \mathrm{ch}}$ к единице происходит с ростом $n_{e} / n_{b}$ не монотонно, а через точку максимума (рис. 9, $b$ ). Положение этого максимума зависит от магнитного числа Рейнольдса $\mathrm{Re}_{m, b}$ на момент входа участка КС в соленоид и лежит между значениями $n_{r b \text {, еq }}$ и $n_{r b \text {, max }}$, соответствующими моментам достижения индукцией поля на оси участка струи индукции внешнего поля $B_{0}$ и максимального значения $B_{c, \max }$ (рис. 5). Значение $T_{J 2, R} / T_{J, \text { ch }}$ в максимуме возрастает примерно от 1.157 при $\mathrm{Re}_{m, b}=0.1$ до 1.962 при $\operatorname{Re}_{m, b}=100$.

Отслеживая изменения $T_{J 1, R} / T_{J, \mathrm{ch}}$ и $T_{J 2, R} / T_{J \text {, ch }}$, отно-

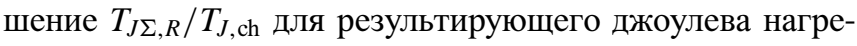
ва КС изменяется в зависимости от $n_{e} / n_{b}$, также проходя через точку максимума и принимая при большой длине соленоида $\left(n_{e} / n_{b} \rightarrow \infty\right)$ значение $T_{J \Sigma, R} / T_{J, \mathrm{ch}}=2$ (рис. 9,c). Значение $T_{J \Sigma, R} / T_{J \text {, ch }}$ в максимуме возрастает c увеличением магнитного числа Рейнольдса $\mathrm{Re}_{m, b}$, составляя примерно 2.101 при $\operatorname{Re}_{m, b}=0.1$ и 2.527 при $\operatorname{Re}_{m, b}=100$. Таким образом, из проведенного анализа джоулева нагрева КС вытекает, что существует оптимальная длина соленоида, при которой обеспечивается максимум температуры нагрева струи.

\section{0. Действие на струю электромагнитных сил}

Для оценки возможности стабилизации растяжения КС вследствие дополнительного силового воздействия на нее со стороны магнитного поля определим обусловленную его влиянием добавку к действующему в струе среднему осевому напряжению, „ответственному“ за развитие пластической неустойчивости струи [31]. Согласно используемой модели несжимаемого жесткопластического цилиндрического стержня, удлиняющегося со скоростью осевой деформации $\dot{\varepsilon}_{z}$ [10], радиальная, окружная и осевая компоненты девиатора напряжений в струе имеют значения $s_{r}=s_{\theta}=-\sigma_{Y} / 3, s_{z}=2 \sigma_{Y} / 3$, где $\sigma_{Y}$ - предел текучести материала струи. Движение частиц КС в радиальном направлении в каждом ее поперечном сечении с учетом действия электромагнитных сил с объемной плотностью $j B$ происходит в соответствии с уравнением

$$
\rho \frac{d v_{r}}{d t}=-\frac{\partial p}{\partial r}+j B
$$

где $p$ - давление в материале струи. Предполагая наружную поверхность КС свободной от действия радиальных напряжений $\sigma_{r}(R)=s_{r}-p(R)=0$, для давления на границе сечения будем иметь значение $p(R)=-\sigma_{Y} / 3$. 
Интегрируя записанное уравнение радиального движения материала КС по радиусу поперечного сечения от некоторого его текущего значения $r$ до значения $R$ с учетом зависимости для радиальной скорости (1), для определения давления в струе получаем соотношение

$$
p(r)=\frac{3}{8} \rho \dot{\varepsilon}_{z}^{2}\left(R^{2}-r^{2}\right)-\frac{\sigma_{Y}}{3}-\int_{r}^{R} j B d r .
$$

Определяя затем осевые напряжения как $\sigma_{z}=s_{z}-p$ и усредняя их по площади поперечного сечения КС

$$
\sigma_{z, \text { av }}=\frac{2}{R^{2}} \int_{0}^{R} \sigma_{z} r d r
$$

для расчета действующего в струе при ее деформировании в магнитном поле среднего осевого напряжения окончательно приходим к зависимости

$$
\sigma_{z, \mathrm{av}}=\sigma_{Y}-\frac{3}{16} \rho \dot{\varepsilon}_{z}^{2} R^{2}+\frac{2}{R^{2}} \int_{0}^{R}\left[\int_{r}^{R} j B d r\right] r d r .
$$

Последнее слагаемое в правой части данной зависимости, отсутствующее при деформировании КС в естественных условиях и обусловленное действием электромагнитных сил, является магнитной составляющей среднего осевого напряжения

$$
\sigma_{z m, \mathrm{av}}=\frac{2}{R^{2}} \int_{0}^{R}\left[\int_{r}^{R} j B d r\right] r d r
$$

которую с использованием закона полного тока в дифференциальной форме (4) можно переписать в виде

$$
\sigma_{z m, \mathrm{av}}=\frac{2}{R^{2}} \int_{0}^{R} \frac{B^{2}}{2 \mu_{0}} r d r-\frac{B_{s}^{2}}{2 \mu_{0}} .
$$

Вычисляя интеграл в представленном выражении с учетом радиального распределения магнитной индукции в КС (10), получаем магнитную добавку к среднему осевому напряжению в струе

$$
\sigma_{z m, \mathrm{av}}=\frac{1}{3}\left(\frac{B_{c}^{2}}{B_{0}^{2}}+\frac{B_{c}}{B_{0}}-2\right) p_{m, \mathrm{ch}}
$$

при движении ее участка в полости соленоида $\left(n_{b} \leq n \leq n_{e}, B_{s}=B_{0}\right)$ и

$$
\sigma_{z m, \mathrm{av}}=\frac{1}{3} \frac{B_{c}^{2}}{B_{0}^{2}} p_{m, \mathrm{ch}}
$$

после выхода из соленоида $\left(n>n_{e}, B_{s}=0\right)$, где для индукции поля на оси КС $B_{c}$ используются зависимости (19) в случае $n_{b} \leq n \leq n_{e}$ и (22) в случае $n>n_{e}$, а величина $p_{m, \text { ch }}$ представляет собой характеристическое магнитное давление для поля с индукцией $B_{0}$ :

$$
p_{m, \mathrm{ch}}=\frac{B_{0}^{2}}{2 \mu_{0}} \text {. }
$$

\section{1. Оценки для условий экспериментов}

Вернемся к экспериментам [21,24] с пропусканием растягивающихся КС через магнитное поле удлиненного соленоида и оценим на основании представленной выше модели применительно к условиям их проведения факторы возможного замедления развития пластической неустойчивости КС, обусловленные индукционным нагревом их материала и действием на них электромагнитных сил. Оценки проведем на примере медной КС, формировавшейся в экспериментах [21] с К3 диаметром $d_{0}=50 \mathrm{~mm}$, для ее среднего участка со скоростью $v_{j}=4 \mathrm{~km} / \mathrm{s}$. Начальные радиус и скорость осевой деформации этого участка, рассчитанные на основании методики, изложенной в [5], составляют $R_{0}=3.5 \mathrm{~mm}$, $\dot{\varepsilon}_{z 0}=2.5 \cdot 10^{5} \mathrm{~s}^{-1}$. При удельном сопротивлении материала участка $\eta=5 \cdot 10^{-8} \Omega \cdot \mathrm{m}$, соответствующем меди, нагретой до температуры примерно $500^{\circ} \mathrm{C}$, магнитное число Рейнольдса для него на момент формирования (18) имело значение $\operatorname{Re}_{m, 0}=19.2$. Расстояние от основания КЗ с кумулятивной выемкой до соленоида $h_{m}$ и длина соленоида $l_{m}$ (рис. 2,a) задавались близкими к реализованным в экспериментах $[21,24]: h_{m}=1.2 d_{0}$, $l_{m}=3 d_{0}$. При данных значениях $h_{m}$ и $l_{m}$ и координате формирования рассматриваемого участка КС относительно основания К3 $z_{f} \approx-0.2 d_{0}$ коэффициенты его удлинения на моменты входа в соленоид и выхода из него

$$
n_{b}=1+\frac{\dot{\varepsilon}_{z 0}}{v_{j}}\left(h_{m}-z_{f}\right), n_{e}=1+\frac{\dot{\varepsilon}_{z 0}}{v_{j}}\left(h_{m}+l_{m}-z_{f}\right)
$$

составляли соответственно $n_{b}=5.38, n_{e}=14.75$.

Представляя в соотношениях (19), (22), (27), (28) текущий коэффициент удлинения участка КС как

$$
n=1+\frac{\dot{\varepsilon}_{z 0}}{v_{j}}\left(z-z_{f}\right)
$$

будем иметь описание эволюции интересующих нас параметров для участка в зависимости от его текущей координаты $z$. На рис. 10 проиллюстрировано изменение индукции магнитного поля на оси рассматриваемого участка КС $B_{c}(19),(22)$, температуры его джоулева нагрева на поверхности $T_{J, R}(27),(28)$ и магнитной составляющей среднего осевого напряжения $\sigma_{z m \text {,av }}(31),(32)$ в зависимости от координаты $z-h_{m}$ участка в процессе его движения, отсчитываемой от точки входа в соленоид. Из рис. 10, $а$ видно, что индукция поля на оси участка сравнивается с индукцией внешнего поля $\left(B_{c} / B_{0}=1\right)$, когда он находится вблизи середины соленоида, и перед выходом из него достигает своего максимума $\left(B_{c, \max } / B_{0} \approx 1.13\right)$. В момент выхода из соленоида температура джоулева нагрева на поверхности участка КС составляет $T_{J, R}=0.88 T_{J, \text { ch }}$, достигая предельного значения $T_{J, R}=2.23 T_{J, c h}$ после выхода участка из соленоида и удаления от него на расстояние около диаметра КЗ $d_{0}$. 

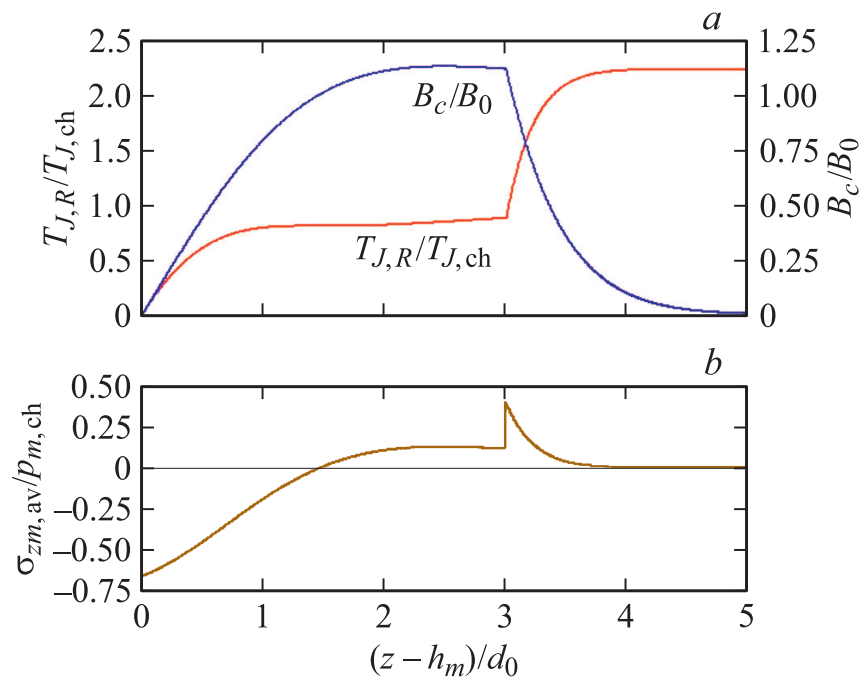

Рис. 10. Изменение магнитной индукции на оси и температуры джоулева нагрева на поверхности $(a)$, а также магнитной составляющей среднего осевого напряжения $(b)$ для участка КС со скоростью $4 \mathrm{~km} / \mathrm{s}$ применительно к условиям проведения экспериментов с воздействием магнитного поля соленоида на КС.

Что касается магнитной добавки к среднему осевому напряжению в участке КС (рис. $10, b)$, то после входа в соленоид до момента выравнивания индукций внешнего поля и поля на оси участка она является отрицательной (участок струи поджимается магнитным полем), имея на момент входа значение $\sigma_{z m \text {,av }}=-0.67 p_{m \text {,ch. После }}$ превышения значения $B_{c}$ над $B_{0}\left(B_{c} / B_{0}>1\right)$ магнитная составляющая среднего осевого напряжения становится положительной (участок КС растягивается электромагнитными силами), доходя до значения $\sigma_{z m \text {,av }}=0.13 p_{m \text {, ch }}$ при движении участка в полости соленоида. В момент выхода участка КС из соленоида происходит резкий кратковременный „всплеск“ значения $\sigma_{z m \text {,av }}$ до $0.41 p_{m, \mathrm{ch}}$, после чего оно эволюционирует к нулю.

В экспериментах [21] индукция создававшегося соленоидом на пути движения КС магнитного поля составляла до 10.5 Т. При таком значении $B_{0}$ характеристическая температура джоулева нагрева (26) материала с теплофизическими свойствами меди $\left(\rho=8900 \mathrm{~kg} / \mathrm{m}^{3}\right.$ : $c=430 \mathrm{~J} /(\mathrm{kg} \cdot \mathrm{K}))$ имеет значение $T_{J, \mathrm{ch}}=11.5 \mathrm{~K}$, а характеристическое магнитное давление (33) составляет $p_{m, \mathrm{ch}}=43.9 \mathrm{MPa}$. Это означает, что в экспериментах [21] усредненная по сечению рассматриваемого участка КС результирующая температура его джоулева нагрева была на уровне всего лишь десяти градусов. Незначительной в сравнении с пределом текучести материала КС $\sigma_{Y}$, которому становится примерно равным действующее в струе осевое напряжение на шеечной стадии ее растяжения (стадии развития пластической неустойчивости) в естественных условиях, была и магнитная добавка к нему $\sigma_{z m \text {,av. }}$ По разным данным [5] предел текучести меди в условиях КС лежит в диапазоне 200-400 МРа.
C учетом этого магнитная составляющая среднего осевого напряжения в рассматриваемом участке КС, не превышавшая практически на всем протяжении по абсолютному значению $0.5 p_{m, \text { ch }}$ (рис. $10, b$ ), была при $B_{0}=10.5$ Т не выше $10 \%$ от значения $\sigma_{Y}$. Как результат, прирост пробивного действия КЗ в экспериментах [21] с воздействием магнитного поля соленоидов на КС был крайне незначительным и не превышал 10\%.

Как указывалось выше, в проводившихся по той же схеме и с КЗ близкого диаметра $\left(d_{0}=56 \mathrm{~mm}\right)$ экспериментах [24] был зафиксирован прирост пробития КЗ на уровне 70\% при индукции магнитного поля соленоида всего лишь $1.7 \mathrm{~T}$, т.е. вшестеро меньшей, чем в части экспериментов [21] с индукцией поля $10.5 \mathrm{~T}$. Так как согласно соотношениям (26), (33), характеристические значения температуры джоулева нагрева и магнитного давления пропорциональны квадрату индукции магнитного поля соленоида, показатели термического и силового механического воздействия магнитного поля на КС были снижены в экспериментах [24] более чем на порядок в сравнении с их максимумами, достигавшимися в экспериментах [21]. Так как в экспериментах [21] даже при значительно большем джоулевом нагреве КС и силовом электромагнитном воздействии на нее их влияние на пробивное действие струи было крайне незначительным, это дает весомые основания предполагать, что истинная причина зафиксированного в экспериментах [24] эффекта существенного увеличения пробития КЗ связана не с растяжением КС в магнитном поле соленоида. С высокой степенью вероятности этой причиной в соответствии с выдвинутой в [39] гипотезой может являться присутствие в облицовке КЗ в момент его подрыва магнитного поля необходимой интенсивности, возникавшего вследствие увеличенного диаметра соленоидов, использовавшихся в экспериментах [24] для создания магнитного поля на пути движения КС.

\section{Заключение}

Предложенная модель эволюции магнитного поля удлиненного соленоида в деформирующейся КС, базирующаяся на допущении о линейности радиального распределения плотности индукционных токов, позволяет провести анализ электромагнитных процессов, происходящих в равномерно удлиняющемся участке струи при его движении в полости соленоида и после выхода из нее, в аналитическом виде. Полученные на основании данной модели результаты в отношении джоулева нагрева материала КС и изменения вследствие действия на струю электромагнитных сил его напряженного состояния, рассматриваемых в качестве факторов возможного замедления развития пластической неустойчивости КС и увеличения ее предельного удлинения при деформировании в магнитном поле, могут служить дополнительным обоснованием гипотезы, предложенной в [39] для объ- 
яснения большого расхождения в приросте пробивного действия К3 по данным экспериментов [21,24].

\section{Конфликт интересов}

Авторы заявляют, что у них нет конфликта интересов.

\section{Список литературы}

[1] Birkhoff G., MacDougall D.P., Pugh E.M., Taylor G.J. // J. Appl. Phys. 1948. Vol. 19. N 6. P. 563-582.

[2] Лаврентьев М.A. // Успехи математических наук. 1957. T. 12. Вып. 4(76). С. 41-56.

[3] Chou P.C., FIis W.J. // Propellants, Explosives, Pyrotechnics. 1986. Vol. 11. N 4. P. 99-114.

[4] Shekhar H. // Central European Journal of Energetic Materials. 2012. Vol. 9. N 2. P. 155-185.

[5] Физика взрыва / Под ред. Л.П. Орленко. В 2-х т. Т. 2. М.: Физматлит, 2004. $656 \mathrm{c.}$

[6] Walters W.P., Zukas J.A. Fundamentals of Shaped Charges. NY: Wiley, 1989. 398 p.

[7] Petit J. // J. Appl. Phys. 2005. Vol. 98. N 12. P. 123521.

[8] Hancock S.L. // Intern. J. Impact Eng. 1999. Vol. 23. N 1(1). P. 353-363.

[9] Svirsky O.V., Vlasova M.A., Korotkov M.I., Krutyakov V.A., Toropova T.A. // Intern. J. Impact Eng. 2003. Vol. 29. N 1-10. P. 683-690.

[10] Бабкин А.В., Ладов С.В., Маринин В.М., Федоров С.В. // ПМТФ. 1997. Т. 38. № 2. C. 3-9. [Babkin A.V., Ladov S.V., Marinin V.M., Fedorov S.V. // J. Appl. Mechan. Tech. Phys. 1997. Vol. 38. N 2. P. 171-176.]

[11] Walsh J.M. // J. Appl. Phys. 1984. Vol. 56. N 7. P. 1997-2006.

[12] Romero L.A. // J. Appl. Phys. 1989. Vol. 65. N 8. P. 30063016.

[13] Бабкин А.В., Ладов С.В., Маринин В.М., Федоров С.В. // ПМТФ. 1999. Т. 40. № 4. C. 25-35. [Babkin A.V., Ladov S.V., Marinin V.M., Fedorov S.V. // J. Appl. Mechan. Tech. Phys. 1999. Vol. 40. N 4. P. 571-580.]

[14] Littlefield D.L., Powell J.D. // Phys. Fluids A: Fluid Dynamics. 1990. Vol. 2. N 12. P. 2240-2248.

[15] Pollock C.E. In: Megagauss Magnetic Field Generation and Pulsed Power Applications. NY: Nova Sci. Publ., 1994. P. 309-316.

[16] Павловский А.И., Пляшкевич Л.Н., Шувалов А.М., Бродский А.Я. // ЖТФ. 1994. Т. 64. Вып. 2. С. 76-82.

[17] Матросов А.Д., Швецов Г.А. // ПМТФ. 1996. Т. 37. № 4. C. 9-14. [Matrosov A.D., Shvetsov G.A. // J. Appl. Mechan. Tech. Phys. 1996. Vol. 37. N 4. P. 464-469.]

[18] Appelgren P., Skoglund M., Lundberg P., Westerling L., Larsson A., Hurtig T. // J. Appl. Mechan. 2010. Vol. 77. N 1. P. 1-7.

[19] Федоров С.В., Бабкин А.В., Ладов С.В. // Физика горения и взрыва. 1999. Т. 35. № 5. С. 145-146. [Fedorov S.V., Babkin A.V., Ladov S.V. // Combustion, Explosion, and Shock Waves. 1999. Vol. 35. N 5. P. 598-599.]

[20] Littlefield D.L. // Phys. Fluids A: Fluid Dynamics. 1991. Vol. 3. N 12. P. 2927-2935.

[21] Бабкин А.В., Маринин В.М., Федоров С.В. // Оборонная техника. 1993. № 9. С. 40-46.
[22] Швецов Г.А., Матросов А.Д., Станкевич С.В. // ПМТФ. 2015. T. 56. № 1. C. 150-161. [Shvetsov G.A., Matrosov A.D., Stankevich S.V. // J. Appl. Mechan.Techn. Phys. 2015. Vol. 56. N 1. P. 125-135.]

[23] Ma B., Huang Z.-X., Zu X.-D., Xiao Q.-Q. // Intern. J. Impact Eng. 2016. Vol. 98. P. 88-96.

[24] Ma B., Huang Z., Guan Z., Zu X., Jia X., Xiao Q. // Intern. J. Impact Eng. 2018. Vol. 113. P. 54-60.

[25] Федоров С.В., Болотина И.А., Струков Ю.А. // Вестник МГТУ им. Н.Э. Баумана. Сер. Естественные науки. 2018. № 2. C. 39-59. [Fedorov S.V., Bolotina I.A., Strukov Yu.A. // Herald of the Bauman Moscow State Tech. Univ., Nat. Sci. 2018. N 2. P. 39-59.]

[26] Федоров С.В. // ПМТФ. 2016. Т. 57. № 3. С. 108-120. [Fedorov S.V. // J. Appl. Mechan. Tech. Phys. 2016. Vol. 57. N 3. P. 483-493.]

[27] Федоров С.В., Бабкин А.В., Ладов С.В. // ЖТФ. 2003. Т. 73. Вып. 8. C. 111-117. [Fedorov S.V., Babkin A.V., Ladov S.V. // Tech. Phys. 2003. Vol. 48. N 8. P. 1047-1052.]

[28] Федоров С.В. // Физика горения и взрыва. 2005. Т. 41. № 1. C. 120-128. [Fedorov S.V. // Combustion, Explosion, and Shock Waves. 2005. Vol. 41. N 1. P. 106-113.]

[29] Федоров С.В. // Боеприпасы и высокоэнергетические конденсированные системы. 2008. № S2. C. 73-80.

[30] Shvetsov G., Matrosov A., Fedorov S., Babkin A., Ladov S. // PPPS 2001 - Pulsed Power Plasma Science 2001. 2015. Vol. 1. 1002023. P. 182-186.

[31] Федоров С.В., Бабкин А.В., Ладов С.В. // ИФЖ. 2001. Т. 74. № 2. C. 79-86. [Fedorov S.V., Babkin A.V., Ladov S.V. // J. Eng. Phys. Thermophys. 2001. Vol. 74. N 2. P. 364-374.]

[32] Бабкин А.В., Ладов С.В., Маринин В.М., Федоров С.В. // Химическая физика. 1999. Т. 18. № 10. С. 26-36. [Babkin A.V., Ladov S.V., Marinin V.M., Fedorov S.V. // Russ. J. Phys. Chem. B. 2000. Vol. 18. N 10-11. P. 1805-1822.]

[33] Ma B., Huang Z., Xiao Q., Zu X., Jia X., Ji L. // IEEE Transactions on Plasma Sci. 2017. Vol. 45. N 5. P. 875-881.

[34] Ma B., Huang Z., Guan Z., Jia X., Xiao Q., Zu X. // Intern. J. Mechan. Sci. 2017. Vol. 133. P. 283-287.

[35] Ma B., Huang Z., Zu X., Xiao Q., Jia X. // Modern Phys. Lett. B. 2017. Vol. 31. P. 1750018.

[36] Xiang H., Meng X., Liang C., Yuan X., Lv Q., Lei B., Zhang $Q$. // IEEE Transactions on Plasma Sci. 2019. Vol. 47. N 1. P. 944-951.

[37] Xiao Q.-Q., Huang Z.-X., Zu X.-D., Jia X. // Propellants, Explosives, Pyrotechnics. 2016. Vol. 41. N 1. P. 76-83.

[38] Ayisit O. // Intern. J. Impact Eng. 2008. Vol. 35. N 12. P. 1399 1404.

[39] Федоров С.В., Бабкин А.В., Маринин В.М. // ЖТФ. 2020. T. 90. Вып. 4. С. 637-646. [Fedorov S.V., Babkin A.V., Marinin V.M. // Technical Physics. 2020. Vol. 65. N 4. P. 612621.]

[40] Ландау Л.Д., Лифшии, Е.М. Электродинамика сплошных сред. М.: Наука, 1982. 621 с.

[41] Тихонов А.Н., Самарский А.А. Уравнения математической физики. М.: Наука, 1977. 736 с.

[42] Лебедев Н.Н. Специальные функции и их приложения. М.: Физматгиз, 1963. 358 с. 